\title{
Optimal carbon dioxide insufflation pressure during robot-assisted thyroidectomy in patients with various benign and malignant thyroid diseases
}

Hoon Yub Kim ${ }^{1 \dagger}$, Yoon Ji Choi ${ }^{2+}$, Hae-Na Yu ${ }^{3}$ and Seung Zhoo Yoon ${ }^{3 *}$

\begin{abstract}
Background: Currently, data are not available concerning a safe insufflation pressure that provides a proper view of the surgical field without adverse metabolic and hemodynamic changes in humans undergoing the robot-assisted thyroidectomy bilateral axillo-breast approach (BABA) using the da Vinci robotic surgical system. The purpose of this study was to determine the optimal carbon dioxide $\left(\mathrm{CO}_{2}\right)$ insufflation pressure in patients with various benign and malignant thyroid diseases when using the da Vinci robotic surgical system.

Methods: A total of 32 patients underwent thyroid surgery at $6(n=15), 9(n=15)$, and $12(n=2) \mathrm{mmHg}$. The partial pressure of carbon dioxide $\left(\mathrm{PaCO}_{2}\right), \mathrm{pH}$, cardiac output, heart rate, and mean arterial pressure were measured at baseline, 30 min and 1, 1.5, and 2 hours after $\mathrm{CO}_{2}$ insufflation, and 30 min after desufflation.

Results: $\mathrm{CO}_{2}$ insufflation of $12 \mathrm{mmHg}$ caused severe facial subcutaneous emphysema, hypercarbia, and acidosis during robot-assisted thyroidectomy with BABA. The study was stopped before completion for the patients' safety in accordance with the study protocol. Applying 6- or 9- $\mathrm{mmHg}$ of $\mathrm{CO}_{2}$ insufflation pressure caused increases in $\mathrm{PaCO}_{2}$ and decreases in arterial $\mathrm{pH}$. However, vital signs were stable and $\mathrm{pH}$ and $\mathrm{PaCO}_{2}$ were within the physiologic range during the surgery in the 6- and 9-mmHg groups.
\end{abstract}

Conclusions: We propose that a $\mathrm{CO}_{2}$ insufflation pressure under $10 \mathrm{mmHg}$ in robot-assisted thyroidectomy with BABA is the optimal insufflation pressure for patient safety.

Keywords: Benign and malignant thyroid diseases, Bilateral axillo-breast approach, Da Vinci, Carbon dioxide insufflation, Pressure, Robot-assisted thyroid surgery

\section{Background}

Since endoscopic neck surgery was introduced into clinical practice in 1995 by Gagner [1], robot-assisted thyroidectomy via the bilateral axillo-breast approach (BABA) using the da Vinci robotic surgical system has been successfully used for various benign and malignant thyroid diseases with a low rate of adverse effects and excellent cosmetic outcomes [2,3]. BABA is performed by using two circumareolar ports and two axillary ports, which is

\footnotetext{
* Correspondence: monday1031@yahoo.co.kr

${ }^{\dagger}$ Equal contributors

${ }^{3}$ Department of Anesthesiology and Pain Medicine, College of Medicine, Korea University, Seoul, South Korea

Full list of author information is available at the end of the article
}

useful for identifying anatomy and dissection during surgery $[3,4]$. The endo-wrist function of the instrument in the da Vinci robotic surgical system makes it possible to employ complex techniques, even in difficult areas with limited access.

During laparoscopic surgery, carbon dioxide $\left(\mathrm{CO}_{2}\right)$ gas is usually insufflated into the body cavity, and an electronic variable-flow insufflator controls the insufflation pressure [5]. A higher $\mathrm{CO}_{2}$ insufflation pressure allows a better view of the surgical field. However, because the insufflation pressure can affect the severity of hypercarbia, balancing the insufflation pressure between a better view of the surgical field and preventing hypercarbia is very important. In laparoscopic surgery, the insufflation

\section{Biomed Central}


pressure should be maintained below $16 \mathrm{mmHg}$ in order to prevent significant hypercarbia $[5,6]$.

The use of $\mathrm{CO}_{2}$ insufflation in the neck potentially causes adverse metabolic and hemodynamic changes as well as tachycardia and massive subcutaneous emphysema [7]. According to Bellantone et al., hypercarbia, moderate acidosis, and a slight increase in mean arterial pressure occurred in pigs undergoing endoscopic neck surgery at $15 \mathrm{mmHg}$ [8]. They proposed that $\mathrm{CO}_{2}$ neck insufflation is safe at $10 \mathrm{mmHg}$. Therefore, during endoscopic neck surgery, the authors empirically used 6 $\mathrm{mmHg}$ of $\mathrm{CO}_{2}$ as the maximal $\mathrm{CO}_{2}$ insufflation pressure in BABA endoscopic thyroidectomy [3,4]. However, concrete data supporting the rationale of using $6 \mathrm{mmHg}$ of $\mathrm{CO}_{2}$ insufflation pressure in endoscopic thyroidectomy with BABA have not been published. In addition, no data are currently available concerning a safe insufflation pressure that can provide a proper view of the surgical field without adverse metabolic and hemodynamic changes in humans undergoing robot-assisted thyroidectomy with BABA by using the da Vinci robotic surgical system (RaBABA).

Therefore, the purpose of the present study was to determine the optimal $\mathrm{CO}_{2}$ insufflation pressure in patients undergoing RaBABA.

\section{Methods}

After obtaining approval from the institutional review board and written informed consent, 32 patients with American Society of Anesthesiologists (ASA) physical status I-II undergoing elective RaBABA were randomly assigned to the three groups described below. The ages of the patients ranged from 18 to 60 years.

Patients were randomly assigned to one of the three groups. The groups were named on the basis of the $\mathrm{CO}_{2}$ gas pressure used to insufflate the peritoneal cavity. Patients with previous neck or breast surgery, severe cardiopulmonary disease, morbid obesity, and neck or vertebral abnormality were excluded from this study.

The patients were premedicated with midazolam (2 mg) and glycopyrrolate $(0.2 \mathrm{mg})$ intramuscularly 30 min before anesthesia. Standard monitoring included electrocardiogram, noninvasive arterial blood pressure, pulse oximetry, end-tidal $\mathrm{CO}_{2}$, bispectral index, and expiratory gas concentration. Anesthesia was induced with intravenous propofol and was maintained with $50 \%$ nitrous oxide in oxygen and an end-tidal concentration of 2 to 3 vol\% of sevoflurane. Intravenous rocuronium bromide was used to facilitate tracheal intubation. The radial artery was cannulated with a 20-gauge catheter to monitor arterial blood pressure. The Vigileo ${ }^{\mathrm{TM}}$ System (FloTrac, Edwards Lifesciences, Irvine, CA, USA) was connected to the arterial line to monitor the cardiac index (CI) and cardiac output (CO). Mechanical ventilation was maintained with oxygen with air $\left(\mathrm{FiO}_{2}\right.$ 0.5) at a constant tidal volume $(8 \mathrm{~mL} / \mathrm{kg})$ and frequency (12 breaths $/ \mathrm{min})$ during the study. Lactated Ringer's solution was used for volume replacement during surgery.

If any one of the termination criteria was met during the surgery, insufflation pressure was reduced to below 5 $\mathrm{mmHg}$. If the study was terminated in two consecutive cases within the same group, the study group was excluded and a new randomization code was generated between the remaining groups. The termination criteria of the study were as follows: (1) persistent acidosis $(\mathrm{pH} \leq 7.15)$ or hypercarbia (partial pressure of carbon dioxide $\left(\mathrm{PaCO}_{2}\right) \geq 50 \mathrm{mmHg}$ ) for $30 \mathrm{~min}$; (2) the mean blood pressure decreased to below $50 \mathrm{mmHg}$; (3) the CI decreased to below $2 \mathrm{~L} / \mathrm{min}$; (4) the heart rate increased to over 110 beat/min; and (5) the occurrence of serious adverse events, such as subcutaneous emphysemas, as determined by the attending anesthesiologists.

All operations were performed by a single surgical team. According to previous reports $[3,4]$, the patient was prepared in the supine position with a pillow placed under the shoulders to maintain neck extension with both arms naturally abducted on both sides. After the vital signs were stabilized, base line blood gases and hemodynamic parameters were recorded. The flaps were raised using a vascular tunneler, and bilateral axillary and two circumareolar $8 \mathrm{~mm}$ to $12 \mathrm{~mm}$ ports were inserted. The flap extended from the superior border of the thyroid cartilage to the 4- $\mathrm{cm}$ inferior area under the clavicle and laterally from just beyond the lateral margin of sternocleidomastoid. At this point, $\mathrm{CO}_{2}$ insufflation was performed, the pressure of $\mathrm{CO}_{2}$ insufflation was determined by the designated group, and the time 0 of insufflation was recorded. The working space was maintained by continuous $\mathrm{CO}_{2}$ insufflation pressure. Total thyroidectomy via the BABA approach using the da Vinci robot system was performed using the general methods $[3,4]$.

Heart rate, mean arterial pressure (MAP), $\mathrm{pH}, \mathrm{PaCO}_{2}$ (arterial), $\mathrm{CI}$ and $\mathrm{CO}$ were measured at baseline, $0 \mathrm{~min}$, 30 min, 1 hour, 1.5 hours, and 2 hours after $\mathrm{CO}_{2}$ insufflation and desufflation, and at $30 \mathrm{~min}$ after desufflation.

Statistical analysis was conducted using SigmaStat 3.5 for Windows (Systat Software, Inc., Chicago, IL, USA). Variables between groups were compared using the twosample $t$-test or Mann-Whitney rank sum test. Variables at each time point within a group were compared using repeated measures analysis of variance. A $P$ value $<0.05$ was considered statistically significant.

\section{Results and discussion}

Enrollment, group assignment, and analysis of patients In total, 32 patients were included in this study. These patients were randomly allocated to three groups: the 6- 
mmHg group $(\mathrm{n}=15)$, the $9-\mathrm{mmHg}$ group $(\mathrm{n}=15)$, and the $12-\mathrm{mmHg}$ group $(n=2)$. Severe facial subcutaneous emphysema was observed at 15 and 30 minutes after the initiation of $\mathrm{CO}_{2}$ insufflation in the two patients in whom the surgery was conducted using a $\mathrm{CO}_{2}$ insufflation pressure of $12 \mathrm{mmHg}$. Furthermore, rapid progression of hypercarbia and acidosis was observed. The study was stopped midway in accordance with the termination criteria. In addition, the $12-\mathrm{mmHg}$ group was dropped because two consecutive cases developed severe facial subcutaneous emphysemas, hypercarbia, and acidosis. The remaining patients in the $12-\mathrm{mmHg}$ group were randomly allocated to the other two groups and successfully participated in this study. Statistically significant differences were not observed in any of the variables, including neck circumstance before and after $\mathrm{CO}_{2}$ insufflation, between the two groups (Table 1).

\section{Analysis of hemodynamic parameters}

Differences in MAP, heart rate (HR), CO, and CI were not observed between the groups at any of the time points. After desufflation, the MAP was increased compared to the baseline value in the $9-\mathrm{mmHg}$ group $(P<0.05)$ (Figure 1$)$. The HR of the $9-\mathrm{mmHg}$ group was increased compared to the baseline value at $30 \mathrm{~min}$ after insufflation, but returned to the baseline level after 1 hour (Figure 2). The CO and CI did not show statistically significant differences compared to the baseline values at any of the time points (Figure 3).

\section{Analysis of metabolic parameters}

Patients undergoing surgery did not develop acidosis or hypercarbia in the 6- or 9-mmHg groups (Figures 4, 5). Changes in $\mathrm{pH}$ and $\mathrm{PaCO}_{2}$ were within the physiologic range at each time point. In addition, no differences in $\mathrm{pH}$ and $\mathrm{PaCO}_{2}$ were observed between the groups at any of the time points. In the 6-mmHg group, decreased $\mathrm{pH}$ and increased $\mathrm{PaCO}_{2}$ compared to the baseline value was observed at $30 \mathrm{~min}$ and at 1, 1.5, and 2 hours after insufflation. The $\mathrm{pH}$ and $\mathrm{PaCO}_{2}$ levels returned to the baseline value at $30 \mathrm{~min}$ after desufflation. In the 9-mmHg

Table 1 Demographic characteristics and baseline data

\begin{tabular}{lcc}
\hline & $\mathbf{6 ~} \mathbf{~ m m ~}$ & $\mathbf{9} \mathbf{~ m m H g}$ \\
\hline Age (years) & $46.8 \pm 8.4$ & $36.0 \pm 6.7$ \\
\hline Weight $(\mathrm{kg})$ & $58.4 \pm 6.8$ & $58.5 \pm 6.8$ \\
\hline Height & $158.9 \pm 5.1$ & $160.0 \pm 4.0$ \\
\hline Volume of $\mathrm{CO}_{2}$ insufflation $(\mathrm{L})$ & $1,390.6 \pm 417.3$ & $1,662.3 \pm 553.3$ \\
\hline Duration of $\mathrm{CO}_{2}$ insufflation (min) & $240.3 \pm 48.8$ & $220.6 \pm 49.9$ \\
\hline $\begin{array}{l}\text { Neck circumstance before } \mathrm{CO}_{2} \\
\text { insufflation }\end{array}$ & $16.0 \pm 2.8$ & $15.8 \pm 1.3$ \\
\hline Neck circumstanceafter $\mathrm{CO}_{2}$ insufflation & $16.8 \pm 3.3$ & $16.7 \pm 1.3$ \\
\hline
\end{tabular}

Data are expressed as the mean \pm SD. Statistically significant differences in the variables were not observed between the two groups. group, decreased $\mathrm{pH}$ and increased $\mathrm{PaCO}_{2}$ compared to baseline was observed at $30 \mathrm{~min}$ and 1, 1.5, and 2 hours after insufflation. $\mathrm{PaCO}_{2}$ levels returned to the baseline value at $30 \mathrm{~min}$ after desufflation. However, the $\mathrm{pH}$ was decreased until $30 \mathrm{~min}$ after desufflation.

Our results showed that a $\mathrm{CO}_{2}$ insufflation pressure of $12 \mathrm{mmHg}$ caused severe facial subcutaneous emphysema, hypercarbia, and acidosis during RaBABA. Although applying 6- or 9-mmHg of $\mathrm{CO}_{2}$ insufflation pressure increased $\mathrm{PaCO}_{2}$ and decreased arterial $\mathrm{pH}$, the vital signs were stable and $\mathrm{pH}$ and $\mathrm{PaCO}_{2}$ were within the physiologic range during surgery.

Subcutaneous emphysema is a frequent complication during endoscopic surgery [5,9]. Subcutaneous emphysema aggravates hypercarbia and acidosis because of an increase in the total gas exchange area [10]. Gottlieb et al. [7] reported that massive subcutaneous emphysema, hypercarbia, supraventricular tachycardia, and acidosis occurred in a patient undergoing endoscopic trans-cervical parathyroidectomy at a $\mathrm{CO}_{2}$ insufflation pressure of $20 \mathrm{mmHg}$. According to Bellantone et al., hypercarbia, moderate acidosis, and a slight increase in mean arterial pressure occurred in pigs undergoing endoscopic neck surgery at $15 \mathrm{mmHg}$ [7]. In addition, a $\mathrm{CO}_{2}$ insufflation of $15 \mathrm{mmHg}$ caused $\mathrm{CO}_{2}$ accumulation and acute hypercarbia, which can lead to intracranial angiectasis, increased brain blood volume, and subsequent intracranial hypertension $[11,12]$. Therefore, the severe facial subcutaneous emphysema experienced by the two patients in the $12-\mathrm{mmHg}$ group was an anticipated event before the collection of study data. However, because several previous studies [7,8] suggested that using an insufflation pressure of 10 to 15 $\mathrm{mmHg}$ was safe in endoscopic neck surgery in an animal model, we hoped that $12 \mathrm{mmHg}$ would provide a better view of the surgical field without adverse metabolic and hemodynamic changes.

From the surgeon's point of view, $9 \mathrm{mmHg}$ pressure of $\mathrm{CO}_{2}$ insufflation may give us several advantages over 6 mmHg pressure of insufflation when performing RaBABA. First, $9 \mathrm{mmHg}$ insufflation provides wider operative space than $6 \mathrm{mmHg}$ insufflation. Unlike the case with non-articulating linearly moving instruments used in conventional endoscopic thyroidectomy, various kinds of articulating instruments which enable almost 360 degrees of freedom of movement are applied through the robotic arms during robotic thyroidectomy, and to use the articulating instruments effectively a wider operative space is needed than is in conventional endoscopic thyroidectomy. In other words, higher flap and wider operative space are necessary to fully take advantage of robotic arm movements during RaBABA. This wider space may be achieved by the maximal safe $\mathrm{CO}_{2}$ insufflation pressure which turned out to be $9 \mathrm{mmHg}$ in 


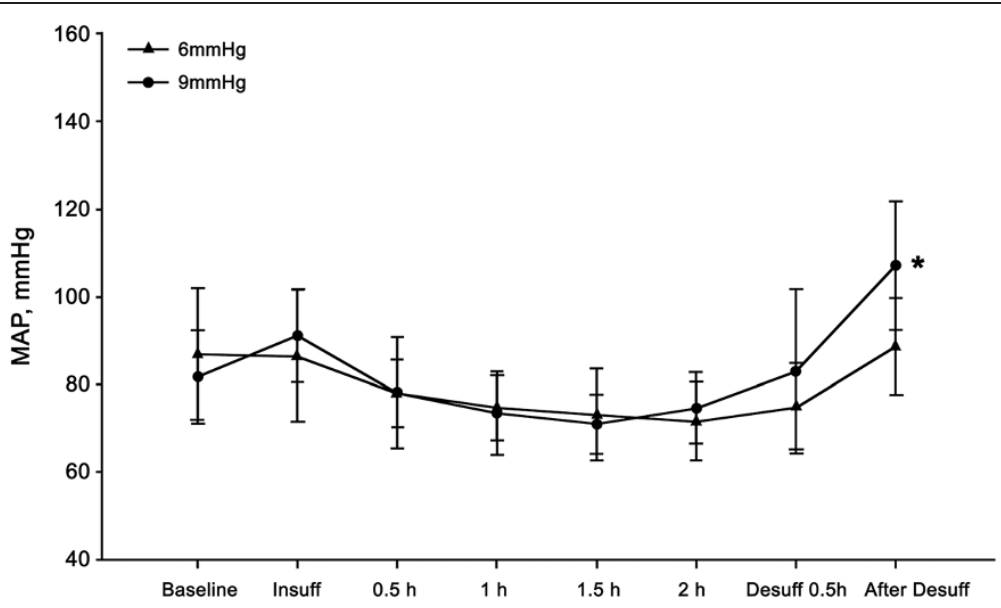

Figure 1 Changes in mean arterial pressure (MAP). A slight increase in MAP at $30 \mathrm{~min}$ after desufflation compared to the baseline $(P<0.05)$ was observed in the $9-\mathrm{mmHg}$ group. Significant differences were not observed between the groups. Data are expressed as the mean \pm SD. * $P<0.05$ versus baseline value.

this study. Second, a higher raised flap in higher $\mathrm{CO} 2$ insufflation pressure helps to keep the surgeon's view clear for a longer time and lessens the need to cleanse the lens of the endoscopic camera during RaBABA. The surgeons performing RaBABA are hindered by the visual disturbance that results from the contamination of the endoscopic camera lens by subcutaneous and subplatysmal fat tissues, especially in obese patients. A more highly elevated flap in $9 \mathrm{mmHg} \mathrm{CO}$ insufflation pressure than in $6 \mathrm{mmHg}$ helps to keep the camera view clear for a longer operative time in these obese patients undergoing RaBABA. Third, in turn, higher insufflation pressure can be somewhat helpful in diminishing the total operation time of RaBABA, especially in obese patients. However, in our study, there was no statistically significant difference in total operation time between the $6 \mathrm{mmHg}$ and $9 \mathrm{mmHg}$ groups $(240.3 \mathrm{~min}$ in the $6 \mathrm{mmHg}$ group versus $220.6 \mathrm{~min}$ in the $9 \mathrm{mmHg}$ group), which might be a result of the limited numbers of enrolled patients in the two groups and also the lack of morbidly obese patients in either group.

Because $\mathrm{CO}_{2}$ has a high solubility, the absorption dose of $\mathrm{CO}_{2}$ is proportional to $\mathrm{CO}_{2}$ pressure and the duration of insufflation [13]. $\mathrm{CO}_{2}$ gas is easily diffused in loose areolar and rough tissue [14], such as in the neck. In previous studies performed in a porcine model, $\mathrm{PaCO}_{2}$ increased and $\mathrm{pH}$ decreased slightly without acidosis or adverse hemodynamic changes in the $10-\mathrm{mmHg}$ group $[8,15]$. In our study, arterial $\mathrm{CO}_{2}$ and $\mathrm{pH}$ were changed after $\mathrm{CO}_{2}$ insufflation in the 6- and 9-mmHg groups.

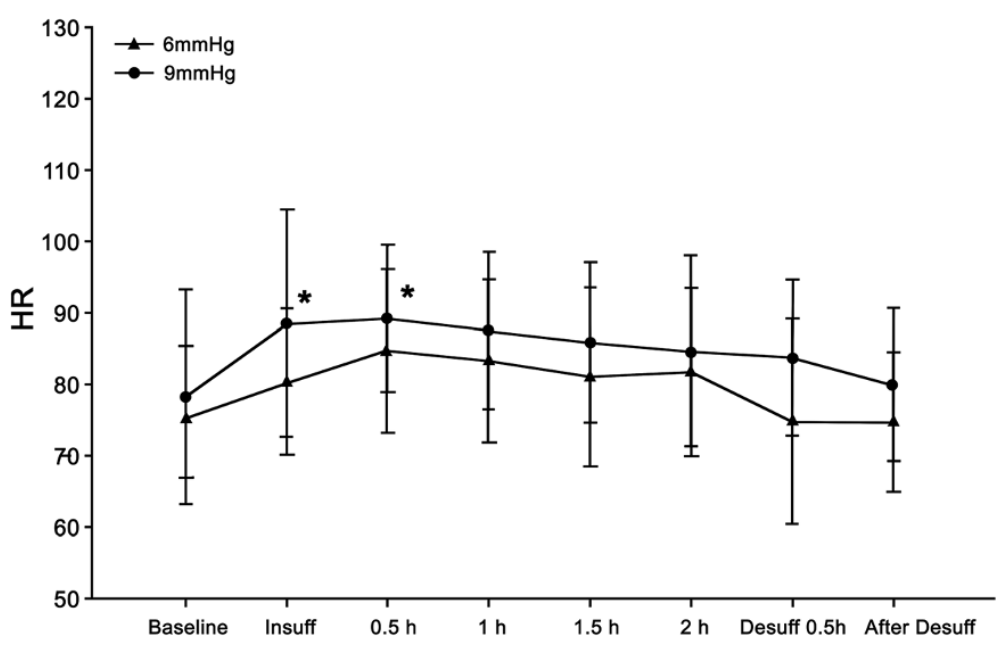

Figure 2 Changes in heart rate (HR). Although a slight increasing trend was observed in HR over time, this change was tolerable. A slight increase in HR at insufflation and 30 min after insufflation compared to the baseline $(P<0.05)$ was observed in the 9 -mmHg group. Significant differences were not observed between the groups. Data are expressed as the mean \pm SD. ${ }^{*} P<0.05$ versus baseline value. 


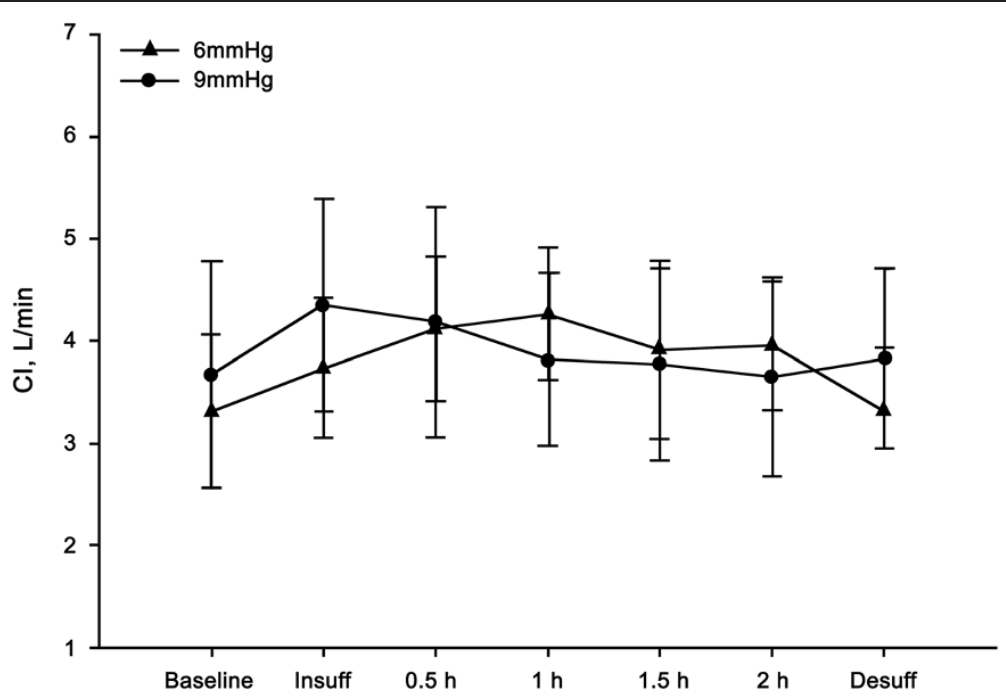

Figure 3 Changes in cardiac output (CO). Changes in CO were tolerable even at $9 \mathrm{mmHg}$ of insufflation. Significant differences were not observed between the groups. Data are expressed as the mean \pm SD.

The increased $\mathrm{PaCO}_{2}$ caused the decrease in $\mathrm{pH}$. However, the changes in $\mathrm{pH}$ and $\mathrm{PaCO}_{2}$ were within the physiologic range in the 6- and $9-\mathrm{mmHg}$ groups during the insufflation period. Hypercarbia due to $\mathrm{CO}_{2}$ insufflation can cause epinephrine and norepinephrine release, resulting in hypertension and tachycardia [16]. However, the blood pressure (BP) response to hypercarbia varies and cannot always be used as a diagnostic sign $[16,17]$. In addition, although tachycardia commonly occurs with hypercarbia during $\mathrm{CO}_{2}$ insufflation $[5,6,16]$, previous studies revealed that changes in HR were inconsistent $[17,18]$. In our study, the BP did not change during the insufflation period but the HR was slightly increased immediately after insufflation. However, the change in HR was tolerable and self-limited.

This study had several limitations. Our results showed that the $\mathrm{CO}$ was not changed in the $6-$ or $9-\mathrm{mmHg}$ groups compared to the baseline value during the study period. The continuous thermodilution technique using a catheter placed in the pulmonary artery is widely used to assess CO in critically ill patients $[19,20]$. Although this method is believed to be quite accurate under most clinical conditions $[21,22]$, the process of acquiring central venous access and a balloon floating through the

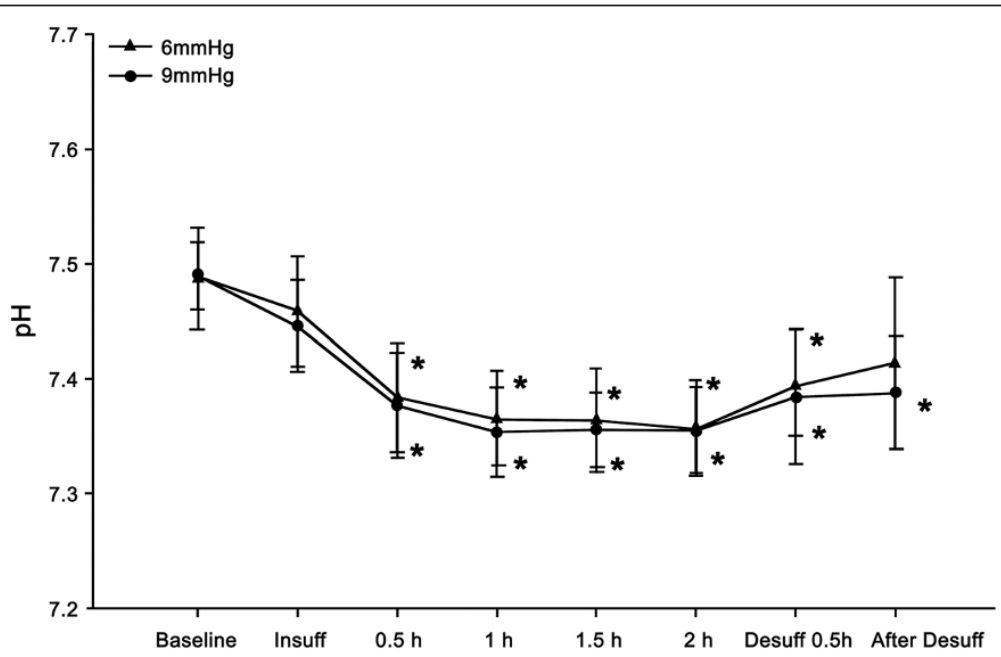

Figure 4 Changes in $\mathbf{p H}$. Decreasing pH was observed at $30 \mathrm{~min}$ and 1, 1.5, and 2 hours after insufflation and desufflation compared to the baseline in the $6-\mathrm{mmHg}$ group $(P<0.05)$. After desufflation, $\mathrm{pH}$ levels returned to the baseline at $30 \mathrm{~min}$ in the $6-\mathrm{mmHg}$ group. Decreasing $\mathrm{pH}$ was observed at $30 \mathrm{~min}$ and at 1, 1.5, and 2 hours after $\mathrm{CO}_{2}$ insufflation and desufflation, and at 30 min after desufflation compared with the baseline in the $9-\mathrm{mmHg}$ group. Significant differences were not observed between the groups. Data are expressed as the mean \pm SD. ${ }^{*} P<0.05$ versus baseline value. 


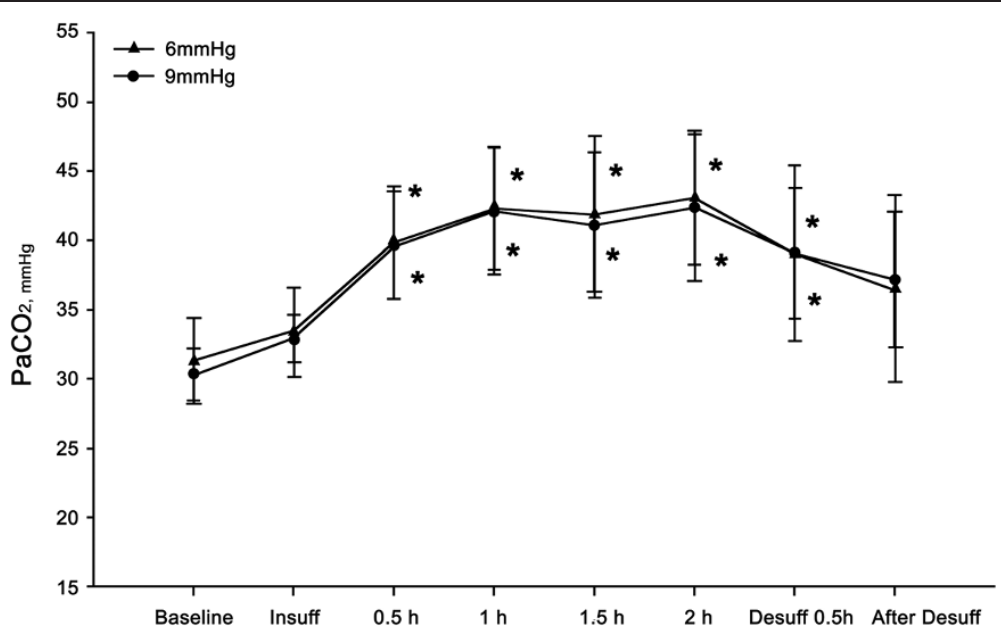

Figure 5 Changes in $\mathrm{PaCO}_{2}$. Increasing $\mathrm{PaCO}_{2}$ was observed at 30 min and 1, 1.5, and 2 hours after insufflation and at desufflation compared with the baseline in the 6- and 9-mmHg groups $(P<0.05)$. At 30 min after desufflation, $\mathrm{PaCO}_{2}$ levels returned to the baseline in the 6- and 9$\mathrm{mmHg}$ groups Significant differences were not observed between the groups. Data are expressed as the mean $\pm \mathrm{SD}$. ${ }^{*} P<0.05$ versus baseline value.

right heart can cause complications, which are sometimes fatal [23,24]. The Vigileo/FloTrac is a valuable tool for the management of patients with diseases such as cardiovascular dysfunction and critical illness or in those undergoing major surgery $[25,26]$ or who are exposed to situations of changing arterial pulse contour [27-29]. Thus, we used the Vigileo/FloTrac to measure CO. A study that used the thermodilution technique with a Swan-Ganz catheter in a porcine model reported that CO increased in the 10-, 15-, and $20-\mathrm{mmHg}$ groups, but these changes were not statistically significant; these results are quite similar to our findings herein.

\section{Conclusions}

In conclusion, we propose that a $\mathrm{CO}_{2}$ insufflation pressure below $10 \mathrm{mmHg}$ in robot-assisted thyroidectomy with BABA is an optimal insufflation pressure.

\section{Abbreviations}

BP: blood pressure; BABA: bilateral axillo-breast approach; Cl: cardiac index; CO: cardiac output; HR: heart rate; MAP: mean arterial pressure; RaBABA: robotic bilateral axillo-breast approach.

\section{Competing interests}

The authors declare that they have no competing interests.

\section{Authors' contributions}

HYK helped conduct the study and write the manuscript, YJC helped analyze the data and write the manuscript, HNY writed the manuscript and SZY helped design the study, conduct the study, analyze the data, and write the manuscript. All authors read and approved the final manuscript.

\section{Acknowledgments}

This work was supported by the Industrial Strategic Technology Program of the Ministry of Knowledge Economy (10041120) and the Korea University Grant.

\section{Author details}

${ }^{1}$ Department of Surgery, College of Medicine, Korea University, Seoul, South Korea. ${ }^{2}$ Department of Anesthesiology and Pain Medicine, Asan Medical Center, University of Ulsan, Seoul, South Korea. ${ }^{3}$ Department of Anesthesiology and Pain Medicine, College of Medicine, Korea University, Seoul, South Korea.

Received: 23 April 2012 Accepted: 13 September 2012

Published: 27 September 2012

\section{References}

1. Gagner M: Endoscopic subtotal parathyroidectomy in patients with primary hyperparathyroidism. Br J Surg 1996, 83:875.

2. Lee KE, Koo Do H, Kim SJ, Lee J, Park KS, Oh SK, Youn YK: Outcomes of 109 patients with papillary thyroid carcinoma who underwent robotic total thyroidectomy with central node dissection via the bilateral axillo-breast approach. Surgery 2010, 148:1207-1213.

3. Kim SJ, Lee KE, Choe JH, Lee J, Koo do H, Oh SK, Youn YK: Endoscopic completion thyroidectomy by the bilateral axillo-breast approach. Surg Laparosc Endosc Percutan Tech 2010, 20:312-316.

4. Lee KE, Rao J, Youn YK: Endoscopic thyroidectomy with the da Vinci robot system using the bilateral axillary breast approach (BABA) technique: our initial experience. Surg Laparosc Endosc Percutan Tech 2009, 19:e71-e75.

5. Bready LL: Anesthesia for laparoscopic surgery. Curr Rev Clin Anesth 1995, 15:133-144.

6. Holzman M, Sharp K, Richards W: Hypercarbia during carbon dioxide gas insufflation for therapeutic laparoscopy: a note of caution. Surg Laparosc Endosc 1992, 2:11-14.

7. Gottlieb A, Sprung J, Zheng XM, Gagner M: Massive subcutaneous emphysema and severe hypercarbia in a patient during endoscopic transcervical parathyroidectomy using carbon dioxide insufflation. Anesth Analg 1997, 84:1154-1156.

8. Bellantone R, Lombardi CP, Rubino F, Perilli V, Sollazzi L, Mastroianni G, Gagner M: Arterial PCO2 and cardiovascular function during endoscopic neck surgery with carbon dioxide insufflation. Arch Surg 2001, 136:822-827.

9. Gerges FJ, Kanazi GE, Jabbour-Khoury Sl: Anesthesia for laparoscopy: a review. J Clin Anesth 2006, 18:67-78.

10. Worrell JB, Cleary DT: Massive subcutaneous emphysema and hypercarbia: complications of carbon dioxide absorption during extraperitoneal and intraperitoneal laparoscopic surgery-case studies. AANA J 2002, 70:456-461. 
11. Levy B, Bollaert PE, Nace L, Larcan A: Intracranial hypertension and adult respiratory distress syndrome: usefulness of tracheal gas insufflation. $J$ Trauma 1995, 39:799-801.

12. Clark RM, Capra NF, Halsey JH: Method for measuring brain tissue pressure. Response to alteration in pCO-2 systemic blood pressure, and middle cerebral artery occlusion. J Neurosurg 1975, 43:1-8.

13. Sharma KC, Kabinoff G, Ducheine $Y$, Tierney J, Brandstetter RD: Laparoscopic surgery and its potential for medical complications. Heart Lung 1997, 26:52-64. quiz 65-57.

14. Liem MS, Kallewaard JW, de Smet AM, van Vroonhoven TJ: Does hypercarbia develop faster during laparoscopic herniorrhaphy than during laparoscopic cholecystectomy? Assessment with continuous blood gas monitoring. Anesth Analg 1995, 81:1243-1249.

15. Yu W, Li F, Wang Z, Qi X, Li B, Zhang G, Hao X, Hu S: Effects of CO2 insufflation on cerebrum during endoscopic thyroidectomy in a porcine model. Surg Endosc 2011, 25:1495-1504.

16. Joris JL: Anesthetic management of laparoscopy. In Anesthesia. Edited by Miller RD. New York: Churchill-Livingstone; 1994:2011-2029.

17. Huang SJ, Lee CY, Yeh FC, Chang CL: Hypercarbia is not the determinant factor of systemic arterial hypertension during carboperitoneum in laparoscopy. Ma Tsui Hsueh Tsa Chi 1991, 29:592-595.

18. Rademaker BM, Bannenberg JJ, Kalkman JC, Meyer DW: Effect of pneumoperitoneum with helium on hemodynamics and oxygen transport: a comparison with carbon dioxide. J Laparosc Surg Endosc 1995, 5:15-20.

19. Yelderman ML, Ramsay MA, Quinn MD, Paulsen AW, McKown RC, Gillman $\mathrm{PH}$ : Continuous thermodilution cardiac output measurement in intensive care unit patients. J Cardiothorac Vasc Anesth 1992, 6:270-274.

20. Boldt J, Menges T, Wollbruck M, Hammermann H, Hempelmann G: Is continuous cardiac output measurement using thermodilution reliable in the critically ill patient? Crit Care Med 1994, 22:1913-1918.

21. Sandham JD, Hull RD, Brant RF, Knox L, Pineo GF, Doig CJ, Laporta DP, Viner S, Passerini L, Devitt H, Kirby A, Jacka M, Canadian Critical Care Clinical Trials Group: A randomized, controlled trial of the use of pulmonary-artery catheters in high-risk surgical patients. N Engl J Med 2003, 348:5-14.

22. Harvey S, Harrison DA, Singer M, Ashcroft J, Jones CM, Elbourne D, Brampton W, Williams D, Young D, Rowan K: Assessment of the clinical effectiveness of pulmonary artery catheters in management of patients in intensive care (PAC-Man): a randomised controlled trial. Lancet 2005, 366:472-477.

23. Abreu AR, Campos MA, Krieger BP: Pulmonary artery rupture induced by a pulmonary artery catheter: a case report and review of the literature. J Intensive Care Med 2004, 19:291-296

24. Huang L, Elsharydah A, Nawabi A, Cork RC: Entrapment of pulmonary artery catheter in a suture at the inferior vena cava cannulation site. J Clin Anesth 2004, 16:557-559.

25. Godje O, Hoke K, Goetz AE, Felbinger TW, Reuter DA, Reichart B, Friedl R, Hannekum A, Pfeiffer UJ: Reliability of a new algorithm for continuous cardiac output determination by pulse-contour analysis during hemodynamic instability. Crit Care Med 2002, 30:52-58.

26. Button D, Weibel L, Reuthebuch O, Genoni M, Zollinger A, Hofer CK: Clinical evaluation of the FloTrac/Vigileo system and two established continuous cardiac output monitoring devices in patients undergoing cardiac surgery. Br J Anaesth 2007, 99:329-336.

27. Metzelder S, Coburn M, Fries M, Reinges M, Reich S, Rossaint R, Marx G, Rex $S$ : Performance of cardiac output measurement derived from arterial pressure waveform analysis in patients requiring high-dose vasopressor therapy. Br J Anaesth 2011, 106:776-784.

28. Sakka SG, Kozieras J, Thuemer O, van Hout N: Measurement of cardiac output: a comparison between transpulmonary thermodilution and uncalibrated pulse contour analysis. Br J Anaesth 2007, 99:337-342.

29. Biancofiore G, Critchley LA, Lee A, Bindi L, Bisa M, Esposito M, Meacci L, Mozzo R, DeSimone P, Urbani L, Filipponi F: Evaluation of an uncalibrated arterial pulse contour cardiac output monitoring system in cirrhotic patients undergoing liver surgery. Br J Anaesth 2009, 102:47-54.

\section{Submit your next manuscript to BioMed Central and take full advantage of:}

- Convenient online submission

- Thorough peer review

- No space constraints or color figure charges

- Immediate publication on acceptance

- Inclusion in PubMed, CAS, Scopus and Google Scholar

- Research which is freely available for redistribution 